\title{
Vitamin K Deficiency
}

National Cancer Institute

\section{Source}

National Cancer Institute. Vitamin K Deficiency. NCI Thesaurus. Code C99108.

Deficiency of vitamin K. It may lead to bleeding, manifested with ecchymoses, petechiae, and hematomas. In infants it may cause hemorrhagic disease of newborn with intracranial and retroperitoneal bleeding. 